\title{
UJI SPEKTROFOTOMETER UV-VIS PADA PRODUK BLENDING KRISTAL CAIR KOLESTERIL AKRILAT DENGAN KRISTAL CAIR TIPE ESTER BENZOAT
}

\author{
Ahmad Faizurrahman Umeir $^{1}$, Afrizal $^{1}$, dan Asep Riswoko ${ }^{2}$ \\ ${ }^{1}$ Jurusan Kimia, Fakultas Matematika IImu Pengetahuan Alam, Universitas Negeri Jakarta. Jl. Pemuda No. 10 \\ Rawamangun, Jakarta 13220 \\ ${ }^{2}$ Sentra Teknologi Polimer (STP)-Badan Pengkajian dan Penerapan Teknologi (BPPT), Jakarta \\ Corresponding author: umeir10@ymail.com
}

\begin{abstract}
Abstrak
Uji Spektrofotometer UV-Vis produk blending Kristal Cair Kolesteril Akrilat (KA) dengan Kristal Cair Tipe Ester Benzoat (KCTEB) telah dilakukan dengan tujuan untuk mendapatkan produk blending yang mampu menyerap cahaya pada panjang gelombang UV. KCTEB diperoleh dari sintesis antara prekursor asam akriloiloksi benzoat (ABB) dan prekursor (S)-(+)-HFM melalui reaksi esterifikasi steglich. Kemudian KCTEB di blending dengan KA pada berbagai variasi komposisi. Komposisi KA:KCTEB sebesar 50:50, 40:60, 30:70, 20:80, dan 10:90. Produk blending di uji dengan menggunakan spektrofotometer UV-VIS dan X-Ray Diffraction (XRD). Hasil uji spektrofotometer UV-VIS menunjukkan produk blending memiliki serapan maksimum pada panjang gelombang yang lebih rendah dibandingkan dengan serapan maksimum KA murni (820 nm). Hal ini menunjukkan bahwa penambahan KCTEB kepada KA dapat mempengaruhi serapan maksimum KA turun pada panjang gelombang yang lebih rendah bahkan sampai pada panjang gelombang sinar UV. Sedangkan uji XRD produk blending 50:50 menunjukkan fasa kolesterik.
\end{abstract}

Kata Kunci: Kristal cair, Blending, Serapan UV.

\section{Abstract}

Test of Product Blending Cholesteryl Acrylate Liquid Crystal (CA) with Liquid Crystal of Ester Benzoate (LCEB) using Spectrophotometre UV-Vis has been done to get the product blending that can have ability absorbance light in UV wavelenght. LCEB was synthesized by Steglich esterification of Acryloilocsy Butiloilocsy Benzoate $(A B B)$ and (S)-(+)-2-HFM. LCEB was blended with CA in various compotition. Compotition of CA:LCEB such as 50:50, 40:60, 30:70, 20:80, and 10:90. Product blending was tested by spectrophotometre UV-Vis and X-Ray Diffraction (XRD). The result from spectrofotometre known that product blending have maximum absorbance in shorter wavelength region than maximum absorbance pure CA (820 nm). It shows that added LCEB to CA can decrease maximum absorbance of CA until walength UV region. The result from XRD known that product blending with compotition of CA:LCEB (50:50) shows cholesteric phase.

Key Words: Liquid Crystal, Blending, UV Absorbance

\section{Pendahuluan}

Kristal cair adalah fasa dari sebuah material yang berada diantara fasa padat dan cair. Keadaan pertengahan antar materi (intermediate) ini biasa disebut "mesofase" atau "mesomorfik". Kristal cair memiliki empat fasa utama, yaitu fasa nematik, smektik, kolesterik, dan diskotik. Sejak penemuannya pada tahun 1888 oleh Friedrich Reinitzer (ahli botani asal Austria), kristal cair berkembang menjadi objek perhatian yang menarik untuk diteliti. Kristal cair kolesterik (Kristal cair kiral nematik) dan Ferroelektrik kristal cair (Kristal cair kiral smektik C) adalah beberapa fasa kristal cair yang menarik untuk diteliti. Kedua fasa kristal cair tersebut dapat dimanfaatkan sebagai material penyusun dari sensor yaitu sebagai penyerap cahaya sinar UV.

Fasa kristal cair kolesterik (KCK) memiliki struktur heliks dan menunjukkan sifat optik yang unik diantaranya rotasi optik yang besar dan refleksi selektif berdasarkan pitch dari struktur heliksnya [1]. Sifat optik tersebut berasal dari kiralitas pada senyawa penyusunnya. Sifat kiral akan membuat bentuk molekul kristal cair menjadi memilin. KCK terdiri dari gugus mesogen, planar cincin, dan rantai alifatik. Panjang pilinan dari molekul kristal cair dinyatakan dengan pitch (P). Nilai picth memiliki korelasi dengan nilai 
panjang gelombang, energi, suhu, dan campuran senyawa kimia lainnya [2].

Fasa ferroelektrik kristal cair (FKC) merupakan kristal cair yang dapat menghasilkan polarisasi listrik tanpa adanya medan listrik. Polarisasi ini dapat dibalikkan oleh pemberian medan listrik yang besarannya bergantung pada temperatur. Selain itu, material ini memiliki struktur polar yang merupakan ciri khasnya, serta bentuk molekulnya yang non-centrosimetrik. Salah satu senyawa yang termasuk ke dalam fasa ferroelektrik kristal cair (fasa kiral smektik C) adalah senyawa kristal cair tipe ester benzoat (KCTEB) yang berhasil disintesis oleh Riswoko dkk. (2011) [3].

Penelitian yang dilakukan Yuwanda (2011) [4] mengatakan bahwa kolesteril akrilat (KA) yang termasuk dalam KCK akan memiliki serapan maksimum pada panjang gelombang UV ketika komposisi SHA (bersifat polar dan termasuk fasa smektik) lebih besar daripada komposisi SFA (bersifat non-polar dan termasuk fasa nematik) dalam blending. Selain itu, Mihara dkk. (2002) [1] mengatakan panjang pitch kolesterik dapat diubah oleh pengaruh eksternal seperti suhu, medan listrik, atau tekanan. Selanjutnya, sejumlah penambahan senyawa kiral juga dapat

mempengaruhi panjang pitch pada fasa kolesterik. Oleh karena itu, perlu dilakukan penelitian mengenai pengaruh penambahan kristal cair tipe ferroelektrik (kristal cair tipe ester benzoat) pada KCK (Kolesteril Akrilat) terhadap kemampuannya dalam menyerap cahaya panjang gelombang tertentu.

Pada penelitian ini dilakukan blending senyawa KA yang termasuk fasa KCK dengan senyawa Kristal cair tipe ester benzoat (KCTEB) pada berbagai variasi komposisi blending. Selanjutnya produk blending dikarakterisasi dengan XRD. Tahap akhir dilakukan uji kemampuan absorbansi gelombang UV-VIS produk blending tersebut menggunakan spektrofotometer UV-VIS.

\section{Metodologi Penelitian}

Metodologi yang digunakan dalam penelitian ini adalah metode eksperimen yang meliputi sintesis kristal cair tipe ester benzoat (KCTEB) dan blending kristal cair. Adapun untuk sintesis merujuk pada kristal cair yang berhasil disintesis oleh Riswoko dkk (2011) [3].

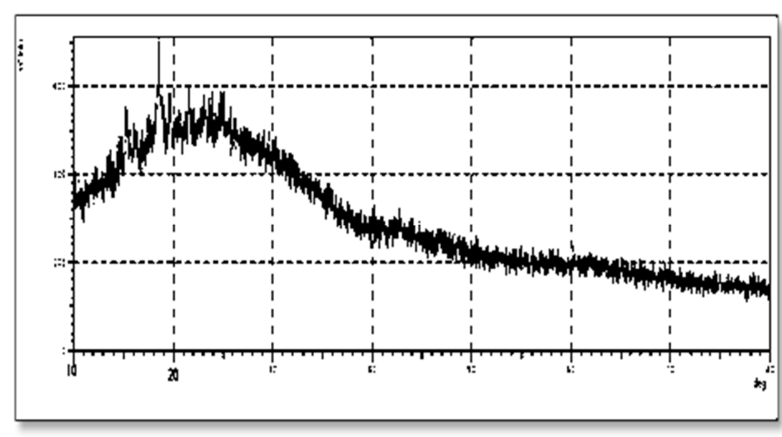

Gambar 1. Spektrum XRD blending variasi 5

a. Blending Kristal Cair Kolesteril Akrilat (KA)

dengan Kristal Cair Tipe Ester Benzoat

(KCTEB)

KCTEB diblending dengan KA pada berbagai variasi komposisi. Variasi komposisi cblending KA:КCTEB yaitu 10:90, 20:80, 30:70, 40:60, dan 50:50. Kelima produk blending diuji dengan menggunakan XRD dan Spektrofotometer UV-Vis.

\section{Hasil dan Pembahasan}

a. Analisis pengukuran produk blending menggunakan spektrofotometer UV-Vis

Karakterisasi produk blending dengan menggunakan spektrofotometer UV-VIS bertujuan untuk mengetahui panjang gelombang dari serapan maksimum produk blending ketika menyerap cahaya. Produk blending diharapkan menyerap cahaya pada panjang gelombang dibawah panjang gelombang Kolesteril Akrilat (820 nm) sampai pada panjang gelombang UV (100-400 nm). Hasil pengukuran masing-masing produk blending dengan menggunakan spektrofotometer UV-VIS ditunjukkan pada Tabel 1. 
Tabel 1. Hasil pengukuran spektrofotometer UVVIS untuk semua variasi blending

\begin{tabular}{|c|c|c|c|}
\hline \multirow{2}{*}{ No } & Nama & $\lambda(\mathrm{nm})$ & \multirow{2}{*}{ Abs } \\
\hline 1 & Blending1 (KA:KCTEB=10:90) & 787.0 & 0,022 \\
\hline 2 & Blending2 (KA:KCTEB=20:80) & 368.0 & 0,105 \\
\hline 3 & Blending3 (KA:KCTEB=30:70) & 359.0 & 0,056 \\
\hline \multirow{2}{*}{4} & \multirow{2}{*}{ Blending4 (KA:KCTEB=40:60) } & 644.0 & 0,026 \\
\cline { 3 - 4 } & & 359.0 & 0,031 \\
\hline \multirow{2}{*}{5} & \multirow{2}{*}{ Blending5 (KA:KCTEB=50:50) } & 802.0 & 0,05 \\
\cline { 3 - 4 } & & 693.0 & 0,052 \\
\hline
\end{tabular}

Berdasarkan hasil yang diperoleh diketahui bahwa seluruh produk blending memiliki kemampuan menyerap cahaya pada panjang gelombang dibawah panjang gelombang KA. Blending 5-3 memiliki serapan maksimum pada panjang gelombang dibawah panjang gelombang serapan maksimum KA murni seperti yang ditunjukkan Tabel 1. Hal ini sesuai literatur bahwa senyawa fasa kolesterik ketika semakin banyak ditambahkan senyawa fasa smektik maka nilai serapan maksimumnya akan berada pada panjang gelombang yang lebih rendah bahkan sampai pada panjang gelombang UV. Senyawa KA memiliki sifat krisal cair fasa kolesterik (tipe nematik memilin) sedangkan KCTEB bertipe kiral smektik. Senyawa tipe smektik ketika dicampurkan kedalam fasa kolesterik akan memilin mengikuti bentuk pilinan fasa kolesterik tetapi tidak dapat terselip diantara fasa kolesterik. Fenomena ini menghasilkan nilai penyerapan lain ketika ditembakkan gelombang UV-VIS bahkan nilai serapannya bisa sampai pada panjang gelombang UV [4].

Tabel 2. Daftar tiga puncak terkuat dari spektrum XRD sampel blending

\begin{tabular}{|c|c|c|}
\hline Peak $2 \theta(\mathrm{deg})$ & $\mathrm{d}(\tilde{\mathrm{A}})$ & FWHM (deg) \\
\hline 18.5075 & 4.79021 & 0.80500 \\
\hline 24.8783 & 3.57609 & 1.22330 \\
\hline 21.5450 & 4.12124 & 0.83000 \\
\hline
\end{tabular}

Namun, hasil pengukuran blending 2 dan blending 1 menunjukkan hasil yang berbeda. Blending 2 menunjukkan serapan maksimum berada pada panjang gelombang (368 nm) dibawah panjang gelombang KA murni $(820$ $\mathrm{nm})$. Tetapi bila dibandingkan dengan blending 3, blending 2 memiliki serapan maksimum pada panjang gelombang yang lebih tinggi dari blending 3 walaupun serapan maksimumnya masih berada pada daerah panjang gelombang UV. Begitu pula dengan blending 1 memiliki serapan maksimum (787 $\mathrm{nm}$ ) pada panjang gelombang yang lebih tinggi bila dibandingkan dengan blending 2 .
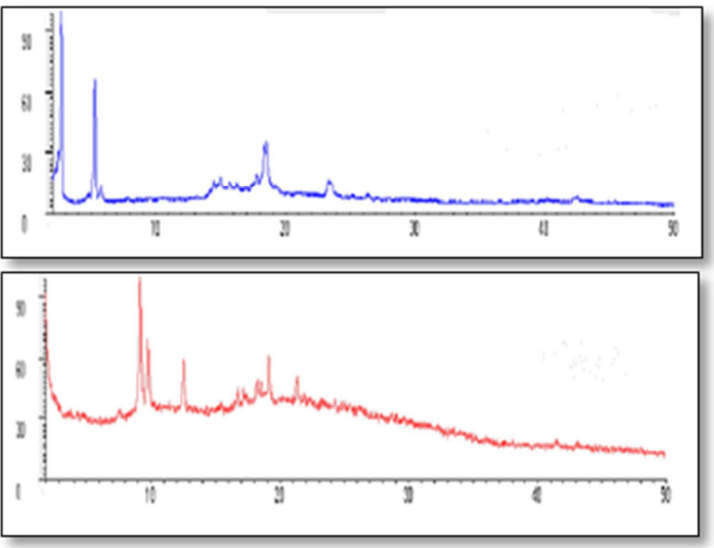

Gambar 2. (a) spektrum XRD KA murni; (b) spektrum XRD KCTEB murni [7]

Hasil tersebut disebabkan oleh berlebihnya senyawa KCTEB. Senyawa KCTEB yang berlebih memungkinkan terjadinya serapan maksimum pada panjang gelombang yang lebih tinggi. Hal ini ditunjukkan oleh penelitian yang dilakukan Steve Leclair dkk tahun 2003 [5], monomer azobenzen dalam THF menunjukkan serapan maksimum pada panjang gelombang $428 \mathrm{~nm}$ namun saat azobenzen sebanyak $5 \%$ direaksikan dengan FLC terjadi perubahan serapan maksimum pada panjang gelombang yang lebih tinngi, yaitu $432 \mathrm{~nm}$. Perlu diingat bahwa senyawa KCTEB termasuk kedalam senyawa FLC sehingga penelitian Steve Leclair dkk [5] mendukung fenomena yang terjasi pada blending 2 dan 1 .

Selain itu, Senyawa KCTEB yang berlebih memungkinkan adanya senyawa KCTEB yang sudah terpolimerisasi. Senyawa KCTEB mudah terpolimerisasi jika ada suhu karena adanya gugus vinyl dalam strukturnya. Senyawa KCTEB dapat terpolimerisasi karena pada suhu $50{ }^{\circ} \mathrm{C}$ 
telah tercapai fasa smektik C, karena senyawa tersebut berlebih maka akan terjadi reaksi antara sesama senyawa KCTEB dibantu dengan suhu sehingga memungkinkan untuk terjadinya polimerisasi. Ketika senyawa KCTEB sudah menjadi polimer maka terjadi fenomena dalam polimer, yaitu adanya jarak antara unit kiral dengan rantai utama polimer. Banyaknya unit kiral dalam polimer akan meningkatkan jarak antara unit kiral dengan rantai utama polimer sehingga menyebabkan polimer terstabilkan pada fasa nematik [6]. Polimer yang terstabilkan pada fasa nematik tersebut artinya mengembalikan serapan maksimum produk blending pada panjang gelombang mendekati KA murni seperti yang ditunjukkan pada hasil pengukuran spektrofotometer UVVIS.

Tabel 3. Puncak-puncak terkuat dari spektrum XRD KA murni [7]

\begin{tabular}{|l|l|l|}
\hline Peak $2 \theta(\mathrm{deg})$ & $\mathrm{d}(\AA)$ & FWHM $(\mathrm{deg})$ \\
\hline 2.7153 & 32.51138 & 0.13970 \\
\hline 5.2992 & 16.66315 & 0.13400 \\
\hline 18.5800 & 4.77168 & 0.22080 \\
\hline
\end{tabular}

Berdasarkan hasil penelitian ini dapat disimpulkan bahwa semakin banyak penambahan senyawa fasa smektik (KCTEB) terhadap senyawa fasa kolesterik (KA) tidak selalu menyebabkan serapan maksimum produk blending turun panjang gelombang yang lebih rendah bahkan sampai pada panjang gelombang UV. Pada penambahan tertentu yaitu komposisi $80 \%$ dan $90 \%$ mulai terjadi serapan maksimum pada panjang gelombang yang lebih tinggi sehingga dapat disimpulkan bahwa penambahan senyawa fasa smektik maksimal untuk meurunkan panjang gelombang serapan maksimum sampai ke panjang gelombang UV adalah $70 \%$. Hasil ini dapat digunakan sebagai informasi untuk aplikasi sensor.

b. Analisis pengukuran produk blending menggunakan XRD
Selanjutnya produk hasil blending diuji dengan menggunakan XRD. Pengujian ini bertujuan untuk memperoleh informasi mengenai struktur dan jenis fasa kristal cair dari produk blending serta melihat jarak antar lapisnya. Langkah awal, salah satu hasil blending (variasi 5) disiapkan untuk dikarakterisasi dengan menggunakan XRD. Sejumlah sampel diletakkan disebuah wadah berbentuk persegi panjang dengan lubang beralas disalah satu sisinya, sampel ditaruh dibagian lubang tersebut. Kemudian wadah sampel dimasukkan kedalam tempatnya didalam XRD. Lalu instrumen XRD mulai running. Gambar 1 menunjukkan spektrum XRD dari sampel blending tersebut.

Tabel 4. Puncak-puncak terkuat dari spektrum XRD KCTEB murni [7]

\begin{tabular}{|l|l|l|}
\hline Peak $2 \theta(\mathrm{deg})$ & $\mathrm{d}(\AA)$ & FWHM $(\mathrm{deg})$ \\
\hline 9.1726 & 9.63350 & 0.20930 \\
\hline 9.7707 & 9.04510 & 0.22610 \\
\hline 12.5389 & 7.05375 & 0.21340 \\
\hline
\end{tabular}

Berdasarkan hasil pengukuran dengan XRD didapatkan sebuah spektrum dengan banyak puncak. Diantara puncak-puncak tersebut tercatat tiga buah puncak yang sangat kuat. Puncak tersebut ditunjukkan pada Tabel 2 dibawah ini.

Untuk melihat daya campur dari kedua senyawa tersebut maka digunakan hasil XRD dari senyawa KA murni dan senyawa KCTEB murni sebagai standar [7]. Hasil XRD KA dan KCTEB murni dapat dilihat pada Gambar 2.

Spektrum XRD akan menunjukkan puncakpuncak terkuat dari spektrum tersebut. Begitu pula dengan spektrum XRD dari KA murni dan KCTEB murni. Puncak-puncak terkuat kedua spektrum XRD tersebut ditunjukkan dala Tabel 3 dan 4.

Berdasarkan hasil pengukuran XRD blending 5 masih terdapat puncak KA murni yang muncul di spektrum XRD tersebut. Hal ini ditunjukkan dengan adanya puncak pada derajat 18.5075 deg yang merupakan salah 
satu puncak pada spektrum XRD KA murni. Interpretasi spektrum fasa kolesterik diperjelas oleh Jui-Hsiang Liu dkk [8] yang mengatakan bahwa puncak broad lemah pada sudut $2 \theta=17-21^{\circ}$ dapat diamati untuk struktur smektik, nematik, dan kolesterik.

Selain itu, spektrum XRD juga menunjukkan puncak pada sudut $2 \theta 21.5450^{\circ}$ dan $24.8783^{\circ}$. Bila melihat spektrum XRD KCTEB murni, spektrum XRD blending 5 tidak menunjukkan adanya puncak dari KCTEB. Namun, seperti yang dijelaskan oleh Jui-Hsiang Liu dkk [8] bahwa puncak pada sudut $2 \theta=21^{\circ}$ merupakan puncak dari fasa smektik, nematik ataupun kolesterik. Hal ini memperkuat bahwa blending 5 termasuk ke dalam fasa kolesterik. Sedangkan puncak pada sudut $24.8783^{\circ}$ merupakan puncak baru yang tidak ada pada spektrum XRD KA murni dan KCTEB murni. Spektrum ini menandakan bahwa blending 5 telah membentuk struktur baru yang memungkinkan perubahan panjang gelombang blending 5 .

Ketiga puncak tertinggi yang ditunjukkan oleh spektrum XRD mempunyai nilai d masingmasing. Nilai $d$ ini menunjukkan jarak antar lapis dari struktur blending yang dihasilkan. Melihat nilai $d$ dari tiga puncak tertinggi spektrum XRD blending 5 mempunyai nilai $d$ yang lebih kecil daripada nilai $d$ dari tiga puncak tertinggi spektrum XRD KA murni dan KCTEB murni. Hal ini memperkuat bahwa blending 5 merupakan produk baru hasil campuran kedua senyawa yang menyebabkan serapan maksimumnya berada pada panjang gelombang yang lebih rendah.

\section{Kesimpulan dan Saran \\ Kesimpulan}

Berdasarkan hasil penelitian dapat disimpulkan bahwa Kolesteril Akrilat (KA) ketika diblending dengan kristal cair tipe ester benzoat (KCTEB) menghasilkan suatu produk yang memiliki serapan maksimum pada panjang gelombang yang berbeda dari serapan maksimum KA murni (820 nm). KA mengalami perubahan serapan maksimum sampai ke serapan pada panjang gelombang sinar UV ketika ditambahkan KCTEB. Produk blending yang mampu menyerap cahaya pada panjang gelombang UV adalah produk blending dengan komposisi KA:KCTEB sebesar 30:70 dan 20:80 dengan serapan maksimumnya berada pada panjang gelombang 359 dan $368 \mathrm{~nm}$.

\section{Terima Kasih}

Ucapan terima kasih ditujukan kepada dosen pembimbing, kepada rekan-rekan yang telah membantu hingga penelitian ini dapat dilakukan dengan baik, serta kepada orang tua yang telah mendukung dalam bentuk materil, moril, dan doa.

\section{Daftar Pustaka}

[1] Mihara, T., T. Uedaira, dan N. Koide. 2002. "Fixation of a cholesteric helical structure by the photopolymerization of a cholesteryl derived monomer". Journal of Liquid Crystal, Vol. 29, Issue 6.

[2] Guo, J., F. Liu, L. Zhang, H. Cao, dan H. Yang. 2009. "Preparation and Reflectance Properties of New Cholesteric Liquid Crystalline Copolymers Containing Cholesteryl Group". Beijing 10083

[3] Riswoko, A., Afrizal, dan W. Setioko. 2011. "Sintesis dan Karakterisasi Struktur Kristal Cair Ferroelektrik Tipe Ester Benzoat Turunan dari Asam (S)-(+)-2-Metil Butanoat". Jurnal Sains Materi Indonesia Vol. 12, No. 3, hal : 175-180

[4] Yuwanda, A. 2011. Studi Sifat Optik Pencampuran Sikloheksilfenol dan Sianofenol Pada Kristal Cair Kolesteril Akrilat. Jakarta : Kimia FMIPA UNJ 
[5] Leclair, S., Lizamma Mathew, Martin Giguere, Shahrokh Motallebi, dan Yue Zhao. 2003. "Photoinduced Alignment of Ferroelectric Liquid Crystal Using Azobenzene Polymer Networks of Chiral Polyacrylates and Polymethacrylates". Macromolecules 2003, 36, 9024-9032

[6] Barmatov, E. B., A. YU. Bobrovsky, D. A. Pebalk, M. V. Barmatov, dan V. P. Shibaev. 1999. "Cholesteric Mesophase of the Hydrogen-Bonded Blends of Liquid Crystalline Ionogenic Copolymers with a Low Molecular Weight Chiral Dopant". Chemistry Department, Moscow State University, 119899 Moscow, Russia

[7] Afrizal, Hikam, M., Soegiyono, B., dan Riswoko, A.. 2012. "XRD Pattern of Liquid Crystal Monomer Acrylate that Conjugated with Cholesterol and p-Hydroxyphenyl-2-Methyl Butanoic". J. Chem. Chem. Eng. 6 (2012) 199-208 